\title{
Factors Conditioning Community Utilization of Environmental Education in Tanzania: The Case of Uluguru Mountains, Morogoro Municipality
}

\author{
Joseph Manase \\ Department of Educational Foundations and Continuing Studies, College of Education, the University of Dodoma, Tanzania \\ E-mail: manassehjoseph2@gmail.com
}

Received: 08-03- 2016

Accepted: 15-04-2016

Published: $30-04-2016$

doi:10.7575/aiac.ijels.v.4n.2p.22

URL: http://dx.doi.org/10.7575/aiac.ijels.v.4n.2p.22

\begin{abstract}
In order for the community to bring meaningful and sustainable environmental conservation and change, it must take action in implementing environmental education values acquired from environmental learning programmes and organizations. This study therefore aimed at assessing factors conditioning community implementation of environmental education in forest conservation. Cultural, neoclassical, political-ecology and impoverishment theories were used to guide this study. Case study research design and qualitative approach were employed. A sample of 20 informants was used and data were collected by the use of interview among community members. Content analysis was used in analysis of qualitative data whereby themes were established as sub headings. Findings indicate that land tenure, traditional beliefs (culture), poverty, and community involvements in logging activities are among the factors conditioning community implementation of environmental education values. Others findings were animal hunting and farming. Findings show that Land tenure system, community involvement in logging; traditional beliefs in sacred forests, animal hunting and farm preparation were factors conditioning community implementation of EE in Uluguru Mountains. This implies that these factors are the contributing factors to poor utilization of EE knowledge and therefore continued environmental degradation in the Uluguru Mountains.
\end{abstract}

Keywords: factors, community, implementation, environmental education

\section{Introduction}

Community implementation of environmental education values and principles has for many decades become a challenging stage. It is also a vital stage in most of the environmental education interventions taking place in developing countries including Tanzania (URT, 2007). Most of the studies such as those of (Saul,2014; Karsenty,2010; Manase,2014) prove that different communities in developed and developing world have been facing different challenges in utilizing EE skills acquired from different environmental programs. These challenges range from socio, economic, cultural and technological paradigms. The challenges according to Parrota et al., (2009) range from policy, socio-economical, cultural, technological as well as political and structural factors.

Again, other associated factors can also be observed from financial aspects in environmental education organization. This may involve the procurement of equipment and resources, recruitment of personnel to be trained and facilitate training and allocation of tasks and resources within the collaborating organization Mbarouk (2015). Under the environmental education implementation plan, if resources are not well mobilized, activities determined and control mechanism established for yielding vital environmental conservation outcomes, then it results into inefficient environmental education (PARTICIP, 2014).

Due to the interdependency that exists between the forest resources and its users, successful implementation of EE depends on the identification and understanding of different EE stakeholders, their practices, expectations and interests. Today, many scientists and resource managers agree that the involvement of stakeholders is a key factor for a successful management regime in any environmental conservation regime. The way stakeholders are involved in the process must reflect, or at least address, the existing complexity of the specific context. A comprehensive method that allows doing this is by use of stakeholders analysis on the factors that condition such groups of individuals to utilize or not, EE values and norms.

Three schools of thought exist with regard to the causes of poor implementation of EE and continued deforestation (Abdallah et al., 2007). The impoverishment school, which believes that the major cause of deforestation is 'the growing number of poor. The neoclassical school believes that the major cause is open-access property rights' while the political-ecology school believes; the major cause of deforestation is the capitalist investors who crowd out peasants which ultimately conditions communities to engage in search for alternative life supporting land. In the Marxist 
tradition, capitalism is seen as a dynamic system of creative destruction, prone to generate and resolve partially and temporarily ecological problems like that of deforestation.

Therefore, the situation is seen to be true with the Tanzanian deforestation factors where peasants surrender land to investors and move inside the reserve areas in search for livelihood alternatives. The impoverishment school sees small holders as the principal agents of deforestation. Poverty in many cases has been mentioned in different literature as among others, the source of environmental degradation although in Tanzania the link proves to be indirect. This is because in some cases even individuals who are educated and rich engage in economic activities related to environmental degradation.

The neoclassical school sees various agents such as increasing in population, which create demand for more land and forest products in rural areas, poverty, poor governance, trade liberalization (Engel \& Engel, 2014). Culture theory is also used in guiding the study due to the fact that culture is seen to contribute to the way people perceive and take some things seriously. It is an important determining factor in deciding whether to take action about something or not.

\subsection{Statement of the Problem}

The relevance of understanding factors contributing to environmental degradation has been widely studied by various scholars such as (Mitinje, 2007; Saul, 2014; Karsenty, 2010). For example the study by Mitinje (2008) focused on socio-economic factors contributing to community participation in environmental conservation in Uluguru Mountains. His study found that people in the Uluguru generally, had low level of formal education. This led to low utilization of EE.M, The study of Saul (2014) focused on expansion of environmental education so that people could think critically and culturally but to the contrary majority of the people had no cultural and critical thinking about EE. From the mentioned studies therefore, little emphasis has been made on factors conditioning community utilization of EE knowledge and skills necessary for environmental conservation in the Uluguru Mountains. Understanding these factors creates opportunities for ensuring sustainable environmental conservation and management. On this ground, the objective of this study was to assess factors conditioning community implementation of environmental education in Uluguru Mountains.

\subsection{Research Objective}

The main objective of the study is to explore the "factors conditioning community utilization of environmental education in Tanzania

\section{Method}

Based on the research objectives of this study, the design considered appropriate for the present study was case study design. This design was considered due to its ability of capturing in-depth information through face-to-face interviews. The study employed qualitative approach whereby views and observations of the informants were collected. A sample of 20 informants was selected through purposeful sampling and snowballing techniques. Out of 20 community members who were interviewed, there were 5 elders who were selected due to their many years of experience with the Uluguru Mountains. These elders mostly provided information about tradition and environmental conservation. Content analysis was employed to analyze qualitative data where themes were established into subheadings.

\section{Results}

The main research question addressed the conditioning factors to community implementation of environmental education in Tanzania. Data were presented descriptively according to the themes. Land tenure system, community involvement in logging, traditional beliefs in sacred forests, animal hunting and farm preparation are the themes which were generated.

\subsection{Land Tenure System}

Based on the interview with the informant from Tanzania forest research institute (TAFORI), it was found that most of the land is publicly owned. As he states:

"The system of owning land in these communities is obviously public. The president of the United Republic of Tanzania has the power to revoke ownership and transfer it to a different use. In many places land has been revoked and previous occupants have been compensated. This is one of the important conditioning reason for making decisions to utilize EE knowledge or not". Another interviewee reported that: "Open access land ownership system does not force people to take responsibility in environmental conservation. For the same reason, individuals do not utilize EE knowledge because of lack of a sense of ownership of the forest resources in Tanzania".

\subsection{Community Involvement in Logging for Commercial Purposes}

This has been reported as one of the conditioning factors for community implementation to EE knowledge. Results from interview revealed that logging activities have been a conditioning factor for community implementation of EE values in the Uluguru Mountains. For example it has been difficult to stop deforestation activities since they are linked to income generation through selling of timber for commercial purpose as one of the participants reported that: "The community is highly involved in illegal timber harvesting. It is logical to argue that this due to ineffective utilization or lack of EE knowledge". 
From the interview it was mentioned that most of the sacred forests have been destroyed, as one of them states: "Sacred forests have been highly destroyed and this has led to a lot of problems in the community such as drought associated with lack of rainfall. Sources of rivers have also been destroyed and many areas have water shortages. Traditionally, sacred forests were places where our ancestors used to meet with gods for worship. Now gods have become furious, that's why we are being punished by hunger, drought and other disasters".

Indigenous environmental education has been ignored by the community; therefore they have opted to intrude the traditionally reserved sacred forests. In so doing they have cut down sacred trees which were important worshipping places in the past. Interview with one of the community members reports that: "Mountain fires have also been reported to be a traditional measure of lifespan. If an individual set fire on the Mountain and that fire spread up to the Mountain peak, then he or she proves to still have many years of living"

Superstition therefore seems to contribute to community dishonest of the EE provided in the community; this is a cultural aspect that is associated in one way or another with community traditional beliefs. It also implies that communities need community education in order to change their perception on the way they view environmental conservation. If the situation of not valuing EE continues, there is a likelihood of these Mountains to turn into desert that will result from total deforestation. The natural biodiversity will also be greatly affected.

\subsection{Animal Hunting and Farm Preparation}

Responding to the question on how people hunt animals and prepare their farms in the Uluguru Mountains, one interviewee reported that: Animals hunting in the Uluguru Mountains has been the common practice for many years. This factor is believed to condition communities around not to effectively utilize EE that aims at forest conservation in the Uluguru Mountains. The common hunting practice is fire setting on the Mountains. This practice conditions the community not to utilize EE in forest and wild life conservation since they are highly dependent on it for their livelihoods. Therefore, it can be implied that methods used in animal hunting and farm preparation are not appropriate and they affect EE utilization by the community.

\subsection{Sources of Energy in the Uluguru Mountains}

From interview it was clear that firewood and charcoal are the most commonly used sources of fuel as one of them reports: "We receive educators who teach us about conservation of our trees but when we come to reality we find that we have no alternative source of energy. Therefore the best option for us is to use firewood. We cannot afford gas and electricity after all we do not have any. For this reason we become conditioned to ignore some of the values in order to survive. I suggest that the use of natural gas and efficient charcoal and firewood burners would be a permanent solution to deforestation".

The implication of this is that EE will only be utilized if different alternatives will be put in place for community consumption and also which addresses the needs of the community. Basically traditional believes, hunting activities, community demand for energy, logging and land tenure systems contributes to community ignorance of utilizing EE knowledge provided with the community.

\section{Discussion of Major Findings}

A number of factors in the Uluguru Mountains were believed to have been conditioning community implementation of EE knowledge in different ways.

Findings indicated that land ownership system, was mostly owned publicly while only few community members own it privately. Since the system of land ownership was found to be mostly public, it was likely for the members of the community to assume that resources such as forest could be freely accessed. The public ownership of land is believed to affect effective utilization of EE. Majority of the population who are dependent on the forest resource for their livelihoods, are therefore likely to intentionally ignore EE initiatives that advocates for the protection of the environment.

The findings agree with those of Abdallah (2006), who found that the major cause of deforestation is open-access property rights in relation to the nature of land tenure system of a particular community. In an open access situation, communities exploit the public property with an assumption that such property is public and everyone has the right to access and use. Many communities, especially those in developing countries, whose land ownership system is public, fails to utilize EE successfully as compared to communities with private land ownership, mostly in developed world (URT ,2007).

Also, Simelane (2006) presents similar findings that the indigenous land tenure in most of the African countries is communal. Access to land is based on membership of a land holding community by birth. Right to natural resources such as land, plants, animals and water is often communal. The communal tenure enjoys strong proprietary and security rights to biotic resources in rural areas between and among two or more indigenous settlements respectively. Communal land ownership in developing countries is believed to have caused what Garret Hardin (1998) calls "tragedy of the commons", a situation which results into severe resource depletion because of overgrazing on the common or communal land. 
Again, the findings reflect the United Republic of Tanzania (URT, 2007) report that at the village level, the tenure system involves some element of societal control of land use. Because of this common ownership of land and its resources there arises a pressure on resource exploitation and use which ultimately result into forest degradation. Environmental education initiatives present in the Uluguru Mountains did not take consideration of land ownership system. This fact is probably one of the reasons contributed to their less efficiency in environmental protection efforts in the Uluguru Mountains. Therefore, for the community to engage effectively in EE programmes it obvious that the Government should provide opportunities for private land ownership as a dominant land tenure system.

Findings from interview proved that the community was highly involved in timber activities. These findings are supported by those of Jarret et al, (2005), who argue that because of poor utilization of EE, logging continues and has become an important cause of deforestation in the Uluguru Mountains, Tanzania and in the third world countries. Communities in the Uluguru Mountains are entirely forest dependent and this becomes therefore a conditioning factor in community utilization of EE. Logging activities are seen by the political-ecology school of thought that the major cause of deforestation is the capitalist investment in land forest products. The investors crowd out peasants who again penetrate the forest and engage in timber activities. In the Marxist tradition, capitalism is seen as a dynamic system of creative destruction, prone to generate and resolve partially and temporarily ecological crises like that of deforestation (Marx, 1971).

Traditional believes were found to be the conditioning factor for community utilization of EE in in Tanzania. Sacred forests in the Uluguru Mountains are believed to influence the communities in utilizing EE although very few sacred forests remain in the Uluguru Mountains. Lack of sacred forests is a factor that influences lack of community utilization of EE knowledge effectively. In the past when environmental conservation was highly connected to traditional beliefs, communities were highly obedient to the traditional EE. Currently, there is little connection between tradition and EE.

Therefore, the disappearance of sacred forests in the Uluguru is also an indicator that EE provided has not been promising to enhance protection of even cultural amenities. Additionally, it could be pointed out that the rate of environmental degradation has overpowered the utilization of EE. If EE efforts would have been provided along with provision of knowledge and awareness of sacred forests, the rate of deforestation would have been reduced to a greater extent.

These findings are in line with those of Brown (2014), who argues that the reservation of forest for shrines, and for evil and forbidden bushes has ensured long term conservation of plants for common utilization. Some of the trees were relatively abundant in natural forests in the past when compared with other trees whose fruits or leaves are of little value to rural people. However, lack of consciousness from EE and such reserved forests for shrines in the Uluguru Mountains, it had resulted to deforestation and natural herbs of medicinal value have perished. From this view, it was true that education, especially traditional one, had to be taught alongside with modern education in order to come up with an integrated approach of EE for forest conservation.

Findings show that the main source of energy for the communities living in the Uluguru Mountains was firewood as one of the community members reported:

"Firewood and charcoal are the most commonly used sources of energy".

Also the community appreciated that they usually receive environmental educators who help them master various contents related to forest conservation, but they fail to utilize the skills due to lack of alternatives, therefore the best option for them is to continue using firewood as a source of energy. It can be thought from these findings that though there were different sources of energy like kerosene, natural gas and sometimes electricity in few places of the Uluguru, yet the price of such energy sources are too high for the majority to afford. Therefore, natural gas must be made readily available and for low price, secondly, education on the use of low charcoal and firewood consuming local stoves must be instigated and re-emphasized.

Poverty was also mentioned as an obstacle to successful utilization of EE and therefore a driver to deforestation. These findings coincide with those by Jazairy et al. (2012) who found that there has been a growing recognition of the intimate link between poverty and environmental degradation. It has been argued in these studies that poverty was both the cause and effect of environmental damage and, as such, in order to address the one the other must also be addressed. This is true with the situation of forest degradation in Tanzania. The argument is, increased forest degradation in one way or another is caused by the widening situation of poverty in many areas of Tanzania. Environmental educators, environmental interest groups and the government must therefore be engaged in addressing the ill problem of poverty through EE in order to rescue forests. Therefore, strategies, including feasible policies on poverty reduction should be put in place to rescue the situation.

Again taboos and traditions connected to environment are the cultural issues which are the conditioning factors for implementation of EE in their community. This argument is supported by the findings of (Saul, 2014) who asserted that people are in constant interaction with their environment and just as human behavior affects the environment, the environment also affects human behavior and environmental problems result from environmental practices, which in turn are cultural activities. This implies that both environment and culture are subject to continuous change. People transform their environment as well as culture since neither the environment nor the cultures are static, but rather dynamic. 
The study indicates strong link between theory and findings. The impoverishment theory informs that poverty has a big influence to people's implementation of environmental education. Most of the poor people do not have an alternative livelihood so they spend most of their time struggling for their survival and in so doing they do not have time to implement EE. Political ecology is linked with the logging activities practiced by businessmen; the neoclassical school believes that the major cause is an open-access property right that is linked to land tenure system. Most of the land was found to be publicly owned and therefore become exposed to threats related to human activities.

\section{Conclusion and Recommendations}

The study investigated factors conditioning community utilization of EE. It was found that community involvement in logging, traditional beliefs, poverty, land tenure are among conditioning factors on community utilization of EE knowledge acquired from EE programs. Others are community dependency on firewood and charcoal as main source of energy which if an alternative source of energy such as gas and efficient charcoal and firewood burners would be put in place. Therefore in order for the community to fully participate in community education these factors have to be considered during the implementation of EE programs. It is therefore recommended that further researches to use different data collection tools, more data sources, different data analysis techniques and a large sample and study area.

\section{References}

Abdallah, J.M. (2007). Economic and Productive Efficiency Analysis of Tobacco and Impact on the Miombo Woodlands of Iringa Region in Tanzania: SUA, Morogoro.

Brown, L.R. (2014). Outgoing the earth: The food security challenge in an age of falling water tables and rising temperatures. W.W. Norton\& Company, Inc.

Marx, K. (1971). Preface to A Contribution to the Critique of Political Economy, Tr.S.W. Rwanzaskava, edited by M.Dobb.London:Lawrence \& Whishart.

Engel, J. (2014). Ethics of Environment and Development, Belhaven Press.

Hardin, G. (1998). Extensions of the Tragedy of the Commons. Science 280 (5364): 682. doi:10.1126/science.280.5364.682

Jarrett, R.L., Sullivan, P. J., \& Watkins, N. D. (2005). Developing social capital through participation in organized youth programs: Qualitative insights from three programs. Journal of Community Psychology, 33, 41-55.

Jazzairy, Idriss, Mohiuddin, Allangir and Theresa, P. (2012). The state of world rural poverty. International Fund forAgricultural Development/London: Intermediate Technology Publications

Karsenty, A. (2010). The architecture of proposed REDD schemes after Bali: Facing critical choices, International Forest Policy Review, 10(3).

Mbarouk S.A. (2015). Extent of Community Participation in Educational Projects in Tanzania: A dissertation submitted in partial fulfillment of the requirement for the degree of master of arts in education of The University of Dodoma. Dodoma

Manase J.L. (2014). Effectiveness of environmental education initiatives in Tanzania: A Thesis Submitted in Fulfillments of the Requirement for the Degree of Doctor of Philosophy in Education, of the University of Dodoma, Dodoma.

PARTICIP (2002). Project Cycle Management Handbook, EuroAid Cooperation Office, FT P International Ltd, Finland.

Parrotta, John A., Lim, Hin Fui; Liu, Jinlong; Ramakrishnan, P.S.; Youn, Yeo-Chang (Eds.) (2009). Traditional Forest Knowledge and Sustainable Forest Management in Asia. Forest Ecology and Management 257(10): 1987-2078.

Saul D. (2014.) Expanding environmental education: Thinking critically, thinking culturally. The Journal of Environmental Education 31(2), 5-8.

Simelane, Z. D. (2006).Community response to environmental education initiatives in South Arica: University Press. URT (2007). National Strategy for Growth and Reduction of Poverty. Dar es Salaam: Government Printers. 